\title{
The Global Economic Cost of Osteoarthritis: How the UK Compares
}

\author{
A. Chen, C. Gupte, K. Akhtar, P. Smith, and J. Cobb \\ MSK Lab, Imperial College, London W6 8RF, UK \\ Correspondence should be addressed to A. Chen, alvinm.chen@gmail.com \\ Received 30 May 2012; Accepted 30 August 2012 \\ Academic Editor: Charles J. Malemud
}

Copyright () 2012 A. Chen et al. This is an open access article distributed under the Creative Commons Attribution License, which permits unrestricted use, distribution, and reproduction in any medium, provided the original work is properly cited.

Aims. To examine all relevant literature on the economic costs of osteoarthritis in the UK, and to compare such costs globally. Methods. A search of MEDLINE was performed. The search was expanded beyond peer-reviewed journals into publications by the department of health, national orthopaedic associations, national authorities and registries, and arthritis charities. Results. No UK studies were identified in the literature search. 3 European, 6 North American, and 2 Asian studies were reviewed. Significant variation in direct and indirect costs were seen in these studies. Costs for topical and oral NSAIDs were estimated to be $\mathfrak{E} 19.2$

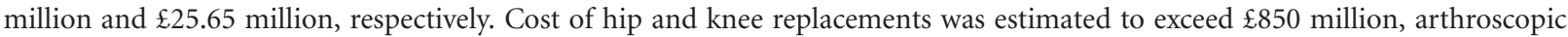
surgery for osteoarthritis was estimated to be $\mathfrak{E} 1.34$ million. Indirect costs from OA caused a loss of economic production over

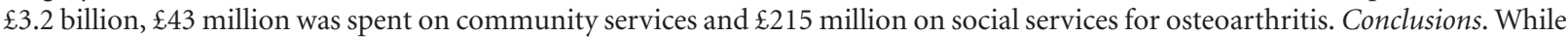
estimates of economic costs can be made using information from non-published data, there remains a lack of original research looking at the direct or indirect costs of osteoarthritis in the UK. Differing methodology in calculating costs from overseas studies makes direct comparison with the UK difficult.

\section{Introduction}

Musculoskeletal diseases remain one of the most common causes for severe long-term pain and disability. The increasing significance of musculoskeletal disorders has prompted the United Nations, the World Health Organization, and 37 countries to spearhead a campaign to recognise and address the burden of musculoskeletal disorders such as arthritis, proclaiming it to be the Bone and Joint Decade (2000-2010) [1], and to advance understanding and treatment of musculoskeletal disorders through prevention, education, and research.

Within the envelope of musculoskeletal disorders, Osteoarthritis represents a complex musculoskeletal disorder with multiple genetic, constitutional, and biomechanical risk factors. It represents the most common form of joint disease and disability in older people and ranks amongst the top 5 causes of disability [2].

The economic costs of osteoarthritis can be broken down into direct costs and indirect costs. Direct costs represent the pharmacological/nonpharmacological treatments, including surgery, as well as use of hospital resources and management of complications arising from the treatment of osteoarthritis. Indirect costs represent loss of time from work, decreased productivity because of pain, care-giver time, premature mortality, and disability compensation/benefits. These costs are summarised in Table 1, below.

A third category sometimes considered is that of intangible costs. These are defined as the pain and suffering experienced by the patient as a result of the disease; the reduction in the patient's quality of life. They remain an area of controversy, with only a few studies making the attempt to estimate them [3].

\section{Aims}

The aim of this paper is to examine all relevant literature on the economic costs of Osteoarthritis in the UK, and to see what comparisons can be made regarding such costs in the UK and other countries in North America, Europe, and Asia. 
TABLE 1

\begin{tabular}{lll}
\hline Direct costs & Indirect costs & Intangible costs \\
\hline Costs of surgery & Loss of productivity & Pain and suffering \\
Hospital resources & Absenteeism & Decreased quality of life \\
Caregiver time & Premature mortality & Potential depression/anxiety \\
Pharmacological and nonpharmacological treatment & Disability payments/benefits & \\
Costs of side effects from treatments & & \\
Research & & \\
\hline
\end{tabular}

\section{Methods}

A comprehensive review of the literature was performed using a computerised bibliographical search of MEDLINE databases from 1946 to 31st Dec 2011. English language articles were reviewed that contained the words "economic cost," "direct cost," or "indirect cost" in combination with "osteoarthritis" in either their title or abstract.

To expand the review beyond only published studies, an internet search was made for publications from the UK Department of Health, the National Institute for Clinical Excellence, the UK National Joint Registry, Hospital Episode Statistics, and charities Arthritis Research (UK) and Arthritis Care, and all publications were reviewed for information on costs for osteoarthritis. Further internet searches were made for publications from the British Orthopaedic Association, the Royal College of Surgeons, the Royal College of Physicians, and the Royal College of General Practitioners. Publications from American Association of Orthopaedic Surgeons and other regional orthopaedic associations in Europe and Asia were also reviewed.

\section{Results}

4.1. What Do We Know about OA Costs in North America? Studies on prevalence of osteoarthritis in the United States have shown that osteoarthritis affects $13.9 \%$ of adults aged 25 and older, and $33.6 \%$ of those over the age of 65 , with an approximate 27 million Americans of all ages suffering from disease [4].

Much of the data available on osteoarthritis in the United States is derived from studies conducted in the 1960s and 1970s. The Framingham study [5] represented one of the early studies to associate increasing age with worsening knee arthritis. This study, which began in 1948, was initially designed to look at cardiovascular risk factors in a representative sample of people in the adult population of Framingham, MA. The study's patients were examined every 2 years since inception. This same cohort of patients was used by Felson et al. to look at the prevalence of knee osteoarthritis approximately 36 years after the start of the study. The age of the patients in the study ranged from 63 to 94, and a total of 1805 patients were studied. The study confirmed that radiographic evidence of OA increased with age, with a higher prevalence of OA changes in women, as well as a significantly higher proportion of women with symptomatic OA.
Lethbridge-çejku et al. [6] examined discharge data from the National Hospital Discharge Survey and concluded that Osteoarthritis accounts for 55\% of all arthritis related hospital admissions, with 409000 such admissions in 1997. The annual cost of knee and hip replacements in 1997 was estimated at $\$ 7.9$ billion ( $£ 4.7$ billion) [6]. Less than 10 years later in 2004, the number of hospital admissions had risen to 632000 and the annual total cost of joint replacements rose to $\$ 22.6$ billion ( $£ 13.8$ billion) [7].

Buckwalter et al. [8] used data drawn from national data sets collected by the U.S. Bureau of Labor Statistics, the U.S. National Center for Health Statistics, as well as existing cost estimates for arthritis in the literature, used proportional attributable risk models and the human capital method to break down costs into direct and indirect costs. From this study, an estimated $\$ 3.4-\$ 13.2$ billion ( $£ 2$ billion$\mathfrak{E} 8$ billion) is spent annually on job-related OA costs in the USA. Meanwhile, Kotlarz et al., in 2010, using evidence from the national health survey data from 1996-2005, looked at absenteeism as a result of osteoarthritis. This study, estimated the indirect cost of the absenteeism to be approximately US\$10.3 billion [9]. The study also confirmed that the costs for women were larger (US\$ 5.5 billion compared to US $\$ 4.8$ billion), and that absenteeism was less in subjects with lower education and those in minority groups.

A survey done by Gupta et al, in ON, Canada in 2005, estimated that the indirect costs incurred by a patient aged over 55 with hip or knee arthritis may be much higher than previously estimated when compared to direct costs (\$12990

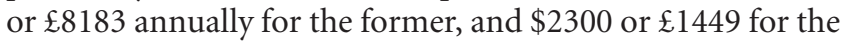
latter) [10]. Indirect costs were incurred mostly for time lost from employment and for unpaid informal caregivers, with caregiver time accounting for $40 \%$ of indirect costs. It should be noted that the authors in this study based the costs on the monthly wage for a professional homemaker or housekeeper as caregiver occupation was unknown. This averaged at US\$ 1278 ( $£ 824$ ) per month, which may explain the relatively higher costs reported.

March and Bachmeier (1997) looked at the global cost of osteoarthritis and found the cost of osteoarthritis in the USA, Canada, UK, France, and Australia to account for between 1$2.5 \%$ of the gross national product (GNP) for those countries [11].

4.2. How Do Recent Studies in Europe Compare? Loza et al., in their Spanish study, assessed the burden of knee and hip osteoarthritis by examining 1071 patients across all the 
provinces of Spain [12]. The average annual cost for OA per patient was estimated at $€ 1502$ ( $£ 1260)$, with direct costs representing $86 \%$ ( $£ 1084)$ of the total cost. Indirect costs were much lower ( $14 \%$ or $£ 176)$ and mainly involved domestic help.

In contrast to this, the COART study [13] in France attempted to estimate the overall financial cost of osteoarthritis to the country. The study concluded that osteoarthritis remained a major public burden, with direct costs in 2002 exceeding 1.6 billion Euros, about $1.7 \%$ of the expenses of the French Health system. Over 13 million visits were made to physicians for osteoarthritis. Medication costs were 570 million euros and inpatient treatment amounted to 820 million Euros. During the period of the study, 80000 total hip replacements and 38000 total knee replacements were performed per year, at a cost of $€ 5600$ per THR and $€ 4500$ per TKR. The study compared the costs to a previous study by Levy et al. [14] in 1993 and found that the prevalence of the disease had risen by $54 \%$, and the direct medical costs by $156 \%$.

In Italy, Leardini et al. examined the economics of osteoarthritis of the knee in 2004. They used a bottomup method, utilising data collected from each patient, and reviewed patients across 29 medical institutes. They concluded that the direct costs came to €934 (£785) and indirect costs $€ 1236$ (£1039) per patient per year [15].

4.3. Is the Situation Different in Asia? There have been fewer studies with regard to economic costs of osteoarthritis in India, China or Southeast Asia compared with countries in the western hemisphere.

In contrast to the Western literature, Woo et al., in their Hong Kong [16] study estimated that the cost of osteoarthritis accounted for $0.28 \%$ of the GNP of Hong

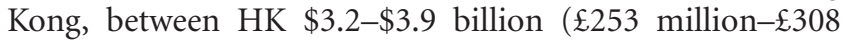
million). The direct costs ranged from HK $\$ 4860-\$ 11180$

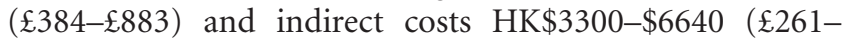
$\mathfrak{E 5 2 5 )}$ per person annually.

Xie et al. assessed indirect costs in Singapore for OA and noted that there were estimated at between US $\$ 1000$ 1200 ( $£ 610-£ 730$ ), around $2.8 \%$ and $3.3 \%$ of the annual household income [3]. The authors here acknowledged that these costs likely represented the lower end of the scale, as costs such as loss of productivity of caregivers were not estimated. The study was also one of the few that attempted to address and estimate intangible costs using the willingness to pay (WTP) method. In economics, this model represents the maximum amount a person would be willing to pay, sacrifice, or exchange in order to avoid something undesired, in this case, the pain and suffering associated with osteoarthritis. The authors here estimated the intangible costs at US\$1200 (£775) per year.

\subsection{What Do We Know about the Economic Cost of $\mathrm{OA}$ in the UK?}

4.4.1. The Prevalence of OA. The Arthritis Research Council (UK) estimated in 2002 that at least 4.4 million patients in the UK have X-ray evidence of moderate-to-severe osteoarthritis in their hands, while 550000 have similar evidence of osteoarthritis in their knees, and 210000 have evidence of this in their hips [17].

Pye et al., in 2004, showed that almost 8.5 million people in the UK have X-ray evidence of osteoarthritis in their spine, with back pain being the most frequent symptom [18]. While predominantly a disease of the elderly, an estimated $6 \%$ of adults aged 30 and above have both knee pain and radiographic changes of osteoarthritis [18].

The Royal College of General Practitioners estimated in 2006 that in the UK over 1 million adults consult their GP each year with symptoms of osteoarthritis [19]. Another study in 2007 showed that consultations for osteoarthritis account for $15 \%$ of all musculoskeletal consultations in those aged 45 and over, rising to $25 \%$ in those aged 75 and over [20]. The cost per consultation is estimated at $\mathfrak{E} 36$ for a 12 minute consultation [21].

During the year from 1999-2000, there were 114,500 hospital admissions related to osteoarthritis in the UK [17]. The latest Hospital Episode Statistics (HES) data (2010-2011) have shown a significant increase in hospital admissions, for hip and knee arthritis alone, the combined figure was 181,350 admissions [20]. When the diagnoses for polyarthritis and "other arthritis"-but not rheumatoid conditions or crystal arthropathy are included, the total number of admissions in 2010/11 was 207,041, representing an $80 \%$ increase compared with figures of 10 years ago.

Surprisingly, there are no published studies in the literature with regard to direct or indirect costs of osteoarthritis in the UK. Data, however, is instead only available from a variety of other sources.

\subsection{What Information Is Available from Other Sources about Costs in the UK?}

4.5.1. Direct Costs. The National Institute of Clinical Excellence (NICE) recently published a costing report in 2008 with regard to implementing the guidelines for treatment of osteoarthritis [22]. In the report, NICE estimated the prevalence of osteoarthritis in the UK to be a total of 2.8 million patients, based on symptomatic diagnosis in patients aged over 45 . The analysis covered the management of osteoarthritis in all such patients.

The cost of topical and oral nonsteroidal antiinflammatories (NSAIDs) was estimated using prescribing data from 2005/06 [22]. An estimated 167000 people who had a diagnosis of osteoarthritis were found to have been prescribed topical NSAIDs, and it was estimated that $50 \%$ (1.4 million patients) of patients with osteoarthritis were prescribed oral NSAIDs. The annual cost in 2005/06

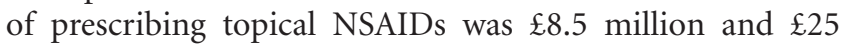
million for oral NSAIDs. The cost for topical NSAID prescriptions was anticipated to double, and the cost of oral treatment reduced by $10 \%$, if the new guidelines are followed. Adjusting for inflation, in 2010 prices, this would

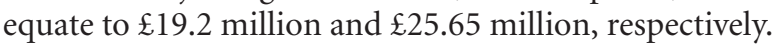

The cost of iatrogenic events related to NSAID use is also substantial. NSAID-related iatrogenic events have been 
estimated to be between $\mathfrak{E} 32-\mathfrak{E} 70$ per patient prescribed an

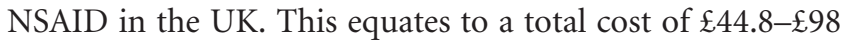

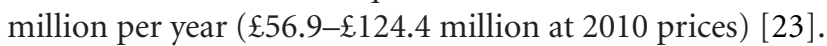

The cost of proton pump inhibitor (PPIs) prescription

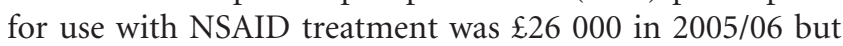
expected to rise significantly to $\mathfrak{£} 10.5$ million ( $£ 11.6$ million in 2010) with implementation of the new guidance.

The 2005/06 Hospital Episode statistics stated that the total number of people aged 45 and over who received arthroscopic lavage and debridement for knee osteoarthritis was approximately 20 000. The national tariff for arthroscopies set by the Health Resource Group in 2008/09 was $\mathfrak{E} 1264$, resulting in a cost $\mathfrak{E} 25$ million for such treatment. It should be noted that NICE expected the cost of this to fall dramatically (by 19000 patients), with guidelines restricting the use of arthroscopic treatment to patients with "mechanical" symptoms such as locking or giving way. The new cost for arthroscopic treatment of osteoarthritis is

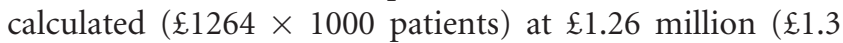
million in 2010).

4.5.2. Economics of Joint Replacement. According to the 8th annual report of the NJR, published September 2011 [22], a 76759 primary total hip replacements were performed in 2010, a 6\% increase from 2009. The revision "burden" was approximately 11\% with 7852 hips revised in 2010 . A total of 81979 knee replacements were done in 2010, representing an increase of 5.7\% when compared with 2009 . The revision "burden" here was less, at just over $6 \%$ requiring revision in 2010. The proportion of total knee replacements to unicondylar knee replacements and patella-femoral knee replacements have remained largely the same for the last few years.

While there are other causes for joint replacement surgery, osteoarthritis remains the most frequent cause for hip replacement (93\% of primary hip replacements in 2010) and knee replacement ( $97 \%$ of primary knee replacements in 2010).

The costs of hip and knee replacements vary considerably from trust to trust in the UK with no set national price for implants, and the cost also being significantly dependant on length of hospital stay. The tariff reimbursement paid to the trust in one study [24] in 2005/06 was $\mathfrak{E} 6000$ for a primary total hip replacement and $\mathfrak{E} 6800$ for a primary total knee replacement. The national tariff for 2010 was set

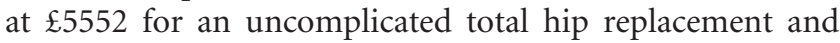
$\mathfrak{E} 5198$ for a similar total knee replacement. This leads to an estimated cost of $\mathfrak{E} 426$ million for total hip replacements and

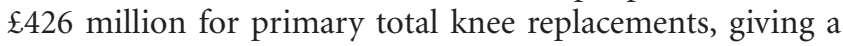
combined total cost for primary hip and knee replacements

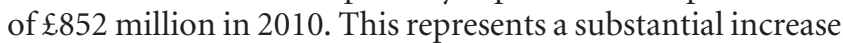
in costs over the last 10 years, when compared to the

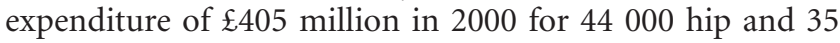
000 knee replacements [17]. Even adjusting for inflation, this cost would only be $\mathfrak{£} 514$ million in 2010 , representing a $66 \%$ increase in the last 10 years. Figure 1 summarises the UK direct costs.

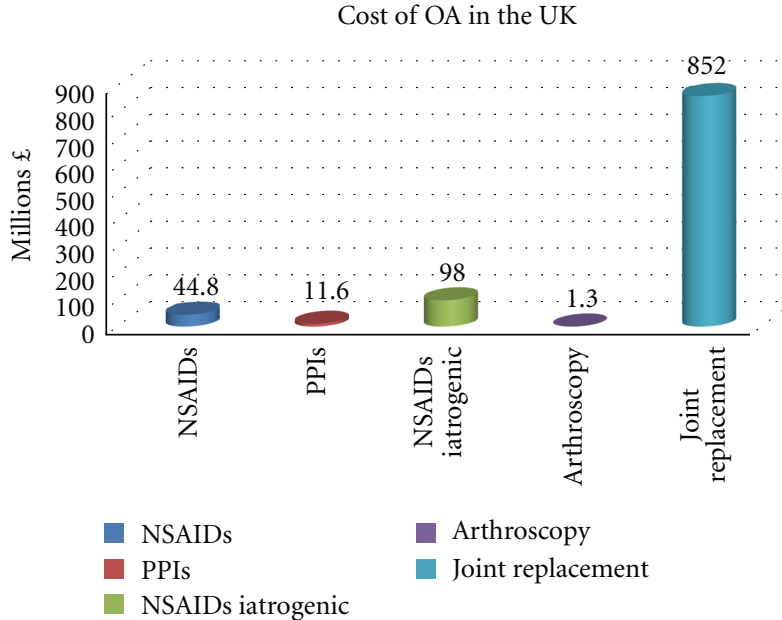

Figure 1

4.5.3. Indirect Costs. Osteoarthritis has a significant negative impact on the UK economy with an estimated total cost of $1 \%$ of GNP [25]. The Department of Work and Pensions estimates that 36 million work days were lost because of osteoarthritis in 2002, resulting in a loss of economic production over $\mathfrak{£} 3.2$ billion; while at the same time, $\mathfrak{} 43$ million was spent on community services and $£ 215$ million spent on social services for osteoarthritis [26].

Arthritis remains the most common condition for people

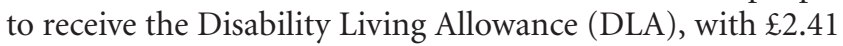
billion paid to people claiming incapacity benefit due to arthritis and related conditions in 2001 [26]. More than half a million people receive the DLA because of arthritis, more than the total for heart disease, stroke, chest disease, and cancer combined [16]. Only around 1 in 200 of those on benefit later returns to work [27].

The most recent review of disability costs in the UK was done by Dame Carol Black [28] in her review of the health of the working age population. Unfortunately, the review did not offer a breakdown of the components in musculoskeletal disability costs, and so, despite the report, the exact contribution of OA to such costs in the UK remains unknown.

\section{Discussion}

The review demonstrates that osteoarthritis represents an increasing economic burden to all countries, both from direct costs and indirect costs. Economic data on osteoarthritis has been made difficult because of problems defining the prevalence and incidence of the disease. There is only sparse literature available regarding economic costs in the east, but what is more surprising is the lack of clear costing studies in the west, especially in the UK.

Direct costs may vary from country to country, which is to be expected given their different health systems, and even between institutions in a country. Significant variability is seen from these studies, making direct comparison difficult. Compounding the problem is the fact that the methodology 
TABLE 2

\begin{tabular}{|c|c|c|c|c|c|}
\hline Author & Year of study & Country & Cost studied & $\begin{array}{l}\text { Individual cost per } \\
\text { annum }(2010 \mathfrak{E}) \text { per } \\
\text { OA patient }\end{array}$ & $\begin{array}{l}\text { Population } \\
\text { cost per annum } \\
(2010 \mathfrak{E})\end{array}$ \\
\hline McClean et al. & 1993 & USA & Direct costs & $\mathfrak{E} 1526$ & US \$548 million \\
\hline Lanes et al. & 1994 & USA & Direct costs & $\mathfrak{E} 496$ & N/A \\
\hline Buckwater et al. & 2000 & USA & Indirect costs & N/A & $\mathfrak{£} 2$ billion- $\mathfrak{£} 8$ billion \\
\hline Kotlartz et al. & 2005 & USA & Indirect costs & $\mathfrak{E} 355$ & 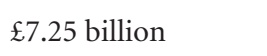 \\
\hline Maetzel et al. & 2000 & Canada & $\begin{array}{l}\text { Direct costs } \\
\text { Indirect costs }\end{array}$ & $\begin{array}{l}\mathfrak{E} 3162 \\
\mathfrak{E} 1407\end{array}$ & $\begin{array}{l}\text { N/A } \\
\text { N/A }\end{array}$ \\
\hline Gupta et al. & 2002 & Canada & $\begin{array}{l}\text { Direct costs } \\
\text { Indirect costs }\end{array}$ & $\begin{array}{l}\mathfrak{E} 1768 \\
\mathfrak{E} 9986\end{array}$ & $\begin{array}{l}\text { N/A } \\
\text { N/A }\end{array}$ \\
\hline Loza et al. & 2003 & Spain & $\begin{array}{l}\text { Direct costs } \\
\text { Indirect costs }\end{array}$ & $\begin{array}{l}\mathfrak{E} 1292 \\
\mathfrak{E} 209\end{array}$ & $\begin{array}{l}\mathfrak{E} 4.04 \text { billion } \\
\mathfrak{E} 654 \text { million }\end{array}$ \\
\hline Le Pen et al. & 2003 & France & Direct costs & $\mathfrak{E} 316$ & $\mathfrak{E} 1.58$ billion \\
\hline Leardini et al. & 2001 & Italy & $\begin{array}{l}\text { Direct costs } \\
\text { Indirect costs }\end{array}$ & $\begin{array}{l}\mathfrak{L} 981 \\
\mathfrak{E} 1299\end{array}$ & $\begin{array}{l}\text { N/A } \\
\text { N/A }\end{array}$ \\
\hline Woo et al. & 2001 & Hong Kong & $\begin{array}{l}\text { Direct costs } \\
\text { Indirect costs }\end{array}$ & $\begin{array}{l}\mathfrak{E} 6561 \\
\mathfrak{E} 620\end{array}$ & $\begin{array}{l}\mathfrak{E} 323 \text { million } \\
\text { (combined cost) }\end{array}$ \\
\hline Xie et al. & 2005 & Singapore & Indirect costs & $\mathfrak{E} 610-\mathfrak{E} 730$ & N/A \\
\hline
\end{tabular}

used in estimating these costs can vary from study to study, and not all studies give a clear breakdown of the calculation of the direct costs involved [29].

Furthermore, in the studies that provide a breakdown of the direct costs, few include the cost of alternative therapies in the treatment of osteoarthritis. There is evidence that nearly half $(47 \%)$ of older patients in one American study [30] used an alternative type of therapy, and these costs are considerable (US\$ 1127 or $£ 723$ per annum). Hence, the true economic burden of direct costs in osteoarthritis is likely to be significantly higher than most of these studies indicate.

The significant variability in indirect costs from these studies is also a concern. This is likely to be due to the lack of a standardized method to estimate indirect costsunfortunately, there remains at present no good evidence to support one preferred method over the others [29]. Most studies conclude that indirect costs, however, represent a largely underestimated economic burden to country, and as such, these estimates may just be the tip of the iceberg.

\section{Conclusion}

Our review of the literature suggests that while there are a large number of studies on economic costs of osteoarthritis, from multiple countries, the information available in the literature remains patchy and difficult to interpret. Some studies focus on the macroeconomic angle, looking at costs at a national scale or costs per capita while others focus on costs from the view of the individual patient with OA. Other studies are only specific for arthritis of a single joint. Even with studies compatible from this point of view, the varied methodology and lack of standardization of costing make it impossible to accurately compare economic costs, whether direct or indirect. These studies are summarized in Table 2.

Despite such difficulties, one conclusion does seem clear from these studies: that such costs are very substantial and are continuing to rise.

The continuing lack of published data regarding direct and indirect OA costs in the UK, especially from the patient perspective, shows that more research into this area is vital. This will allow us to fully appreciate the healthcare burden of $\mathrm{OA}$ in the UK, as well as to make more accurate financial planning for the provision for healthcare services for the treatment of $\mathrm{OA}$ in the subsequent decade to come.

\section{References}

[1] A. D. Woolf and B. Pfleger, "Burden of major musculoskeletal conditions," Bulletin of the World Health Organization, vol. 81, no. 9, pp. 646-656, 2003.

[2] C. J. L. Murray and A. D. Lopez, "Global mortality, disability, and the contribution of risk factors: global burden of disease study," The Lancet, vol. 349, no. 9063, pp. 1436-1442, 1997.

[3] F. Xie, J. Thumboo, K. Y. Fong et al., "A study on indirect and intangible costs for patients with knee osteoarthritis in Singapore," Value in Health, vol. 11, no. 1, pp. 84-90, 2008.

[4] R. C. Lawrence, D. T. Felson, C. G. Helmick et al., "Estimates of the prevalence of arthritis and other rheumatic conditions in the United States. Part II," Arthritis and Rheumatism, vol. 58 , no. 1, pp. 28-35, 2008.

[5] D. T. Felson, A. Naimark, and J. Anderson, "The prevalence of knee osteoarthritis in the elderly. The Framingham Osteoarthritis study," Arthritis and Rheumatism, vol. 30, no. 8, pp. 914-918, 1987. 
[6] M. Lethbridge-Çejku, C. G. Helmick, and J. R. Popovic, "Hospitalizations for arthritis and other rheumatic conditions data from the 1997 National Hospital Discharge survey," Medical Care, vol. 41, no. 12, pp. 1367-1373, 2003.

[7] I. Rosemont, United States Bone and Joint Decade. The Burden of Musculoskeletal Diseases in the United States, American Academy of Orthopaedic Surgeons, Rosemont, Ill, USA, 2008.

[8] J. A. Buckwalter, C. Saltzman, and T. Brown, "The impact of osteoarthritis: implications for research," Clinical Orthopaedics and Related Research, supplement 427, pp. S6-S15, 2004.

[9] H. Kotlarz, C. L. Gunnarsson, H. Fang, and J. A. Rizzo, "Osteoarthritis and absenteeism costs: evidence from US national survey data," Journal of Occupational and Environmental Medicine, vol. 52, no. 3, pp. 263-268, 2010.

[10] S. Gupta, G. A. Hawker, A. Laporte, R. Croxford, and P. C. Coyte, "The economic burden of disabling hip and knee osteoarthritis (OA) from the perspective of individuals living with this condition," Rheumatology, vol. 44, no. 12, pp. 15311537, 2005.

[11] L. M. March and C. J. M. Bachmeier, "Economics of osteoarthritis: a global perspective," Bailliere's Clinical Rheumatology, vol. 11, no. 4, pp. 817-834, 1997.

[12] E. Loza, J. M. Lopez-Gomez, L. Abasolo, J. Maese, L. Carmona, and E. Batlle-Gualda, "Economic burden of knee and hip osteoarthritis in Spain," Arthritis Care and Research, vol. 61, no. 2, pp. 158-165, 2009.

[13] C. Le Pen, C. Reygrobellet, and I. Gérentes, "Financial cost of osteoarthritis in France: the "COART" France study," Joint Bone Spine, vol. 72, no. 6, pp. 567-570, 2005.

[14] E. Levy, A. Ferme, D. Perocheau, and I. Bono, "Socioeconomic costs of osteoarthritis in France," Revue du Rhumatisme, vol. 60, no. 6, pp. 63S-67S, 1993.

[15] G. Leardini, F. Salaffi, R. Caporali, B. Canesi, L. Rovati, and R. Montanelli, "Direct and indirect costs of osteoarthritis of the knee," Clinical and Experimental Rheumatology, vol. 22, no. 6, pp. 699-706, 2004.

[16] J. Woo, E. Lau, C. S. Lau et al., "Socioeconomic impact of osteoarthritis in Hong Kong: utilization of health and social services, and direct and indirect costs," Arthritis Care and Research, vol. 49, no. 4, pp. 526-534, 2003.

[17] A. R. Council, 2002, Arthritis: The Big Picture, http://www. ipsos-mori.com//Assets/Docs/Archive/Polls/arthritis.pdf.

[18] S. R. Pye, D. M. Reid, R. Smith et al., "Radiographic features of lumbar disc degeneration and self reported back pain," Journal of Rheumatology, vol. 31, no. 4, pp. 753-758, 2004.

[19] Royal College of General Practitioners-Birmingham Research Unit, “Annual prevalence report,” Tech. Rep., 2006.

[20] HES, http://www.hesonline.nhs.uk/Ease/servlet/ContentServer?siteID=1937\&categoryID=203, 2011.

[21] L. Curtis, Unit Costs of Health and Social Care 2009, Personal Social Services Research Unit, The University of Kent, Kent, UK.

[22] N. J. Registry, 8th Annual Report. 2011.

[23] R. A. Moore and C. J. Phillips, "Cost of NSAID adverse effects to the UK national health service," Journal of Medical Economics, vol. 2, pp. 45-55, 1999.

[24] P. Hamilton, M. Lemon, Field, and R. Issue, "Cost of total hip and knee arthroplasty in the UK. A comparison with the current reimbursement system in the NHS," Journal of Bone and Joint Surgery B, vol. 91, supplement 1, article 112, 2009.

[25] H. Arthritis, Arthrtitis in the UK-the Key Facts, 2008.

[26] UK, D. F. w. and P., Disability Living Allowance-cases in payment Caseload (Thousands): Main Disabling Condition by Gender of claimant, http://83.244.183.180/100pc/dla/disabled/ccsex/a_carate_r_disabled_c_ccsex_nov07.html, 2007.

[27] Arthritis and Musculoskeletal Alliance. Standards of care for people with osteoarthritis, http://arma.uk.net/local-groups/ care-documents/osteoarthritis/.

[28] D. C. Black, Working for a Healthier Tomorrow, Transaction, London, UK, 2008.

[29] F. Xie, J. Thumboo, and S. C. Li, "True difference or something else? Problems in cost of osteoarthritis studies," Seminars in Arthritis and Rheumatism, vol. 37, no. 2, pp. 127-132, 2007.

[30] S. D. Ramsey, A. C. Spencer, T. D. Topolski, B. Belza, and D. L. Patrick, "Use of alternative therapies by older adults with osteoarthritis," Arthritis Care and Research, vol. 45, no. 3, pp. 222-227, 2001. 


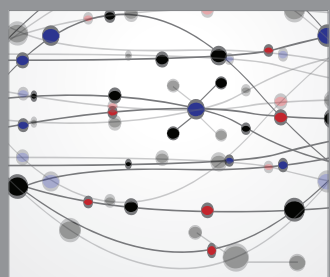

The Scientific World Journal
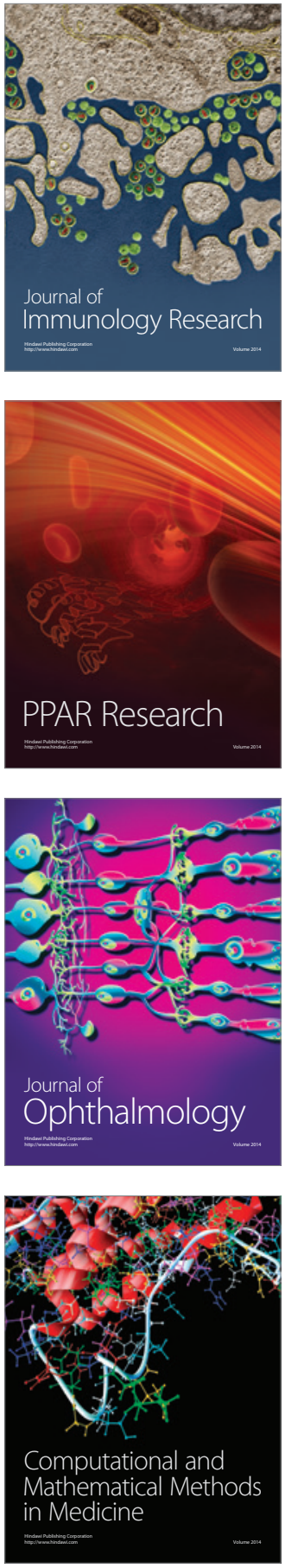

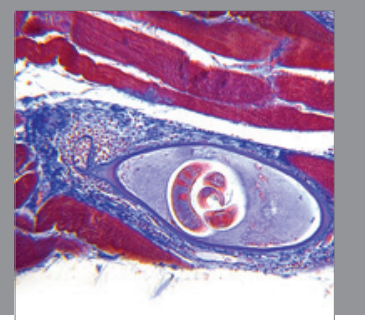

Gastroenterology

Research and Practice
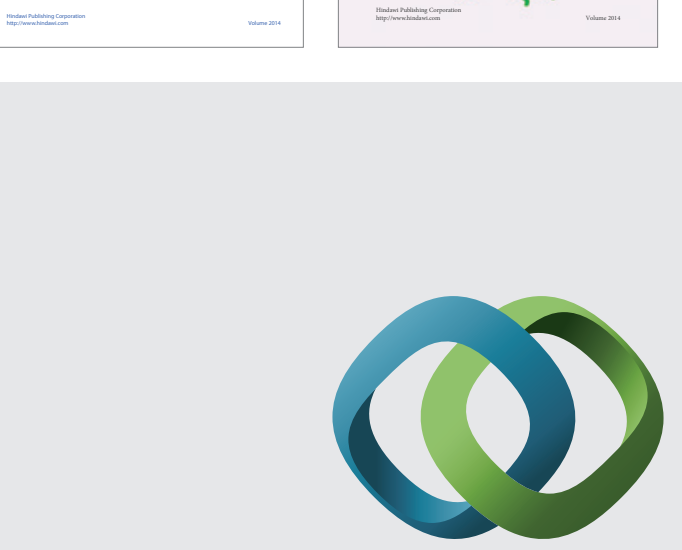

\section{Hindawi}

Submit your manuscripts at

http://www.hindawi.com
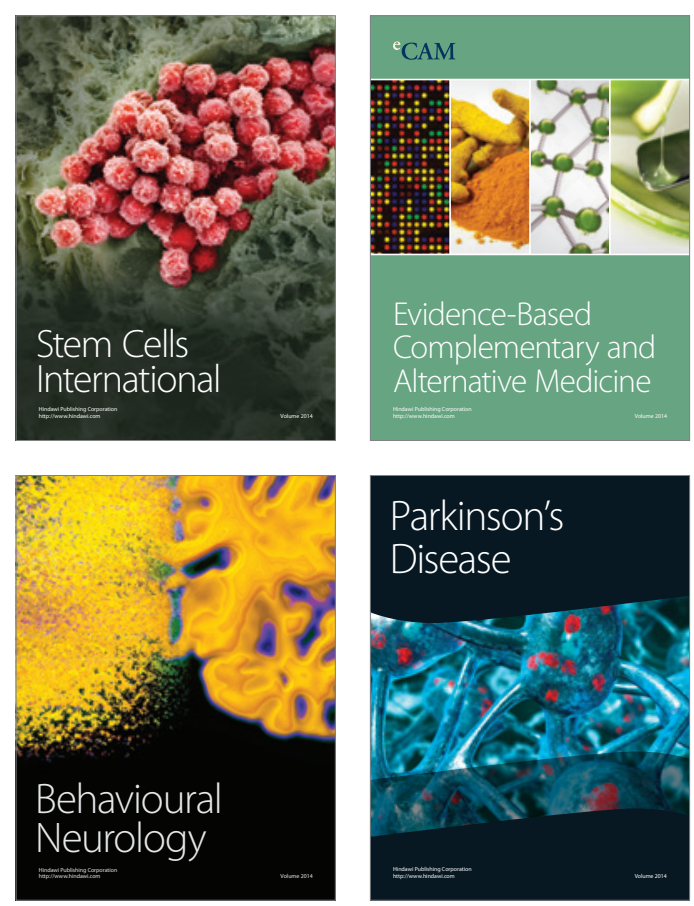

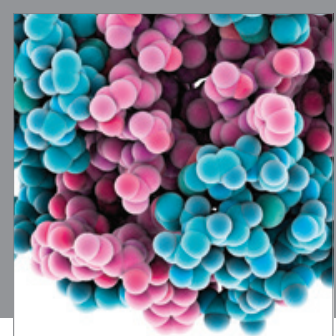

Journal of
Diabetes Research

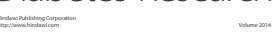

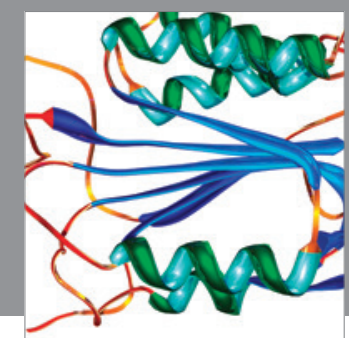

Disease Markers
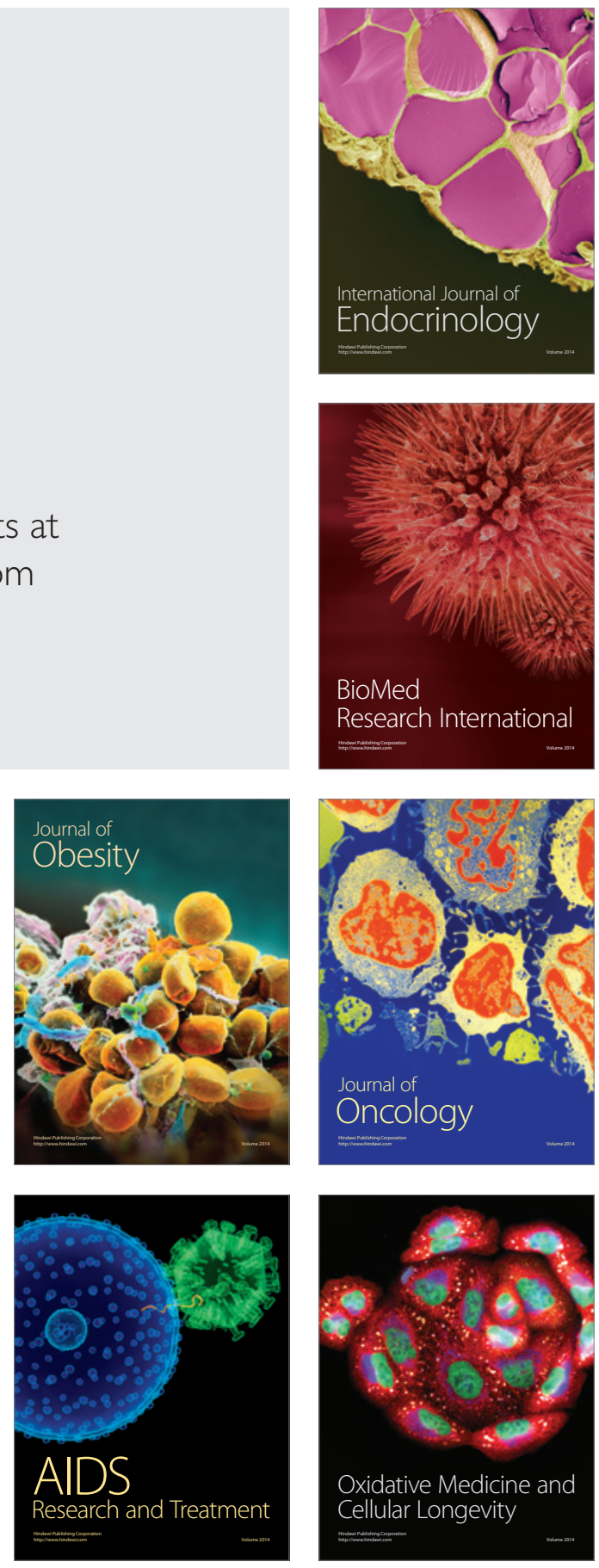